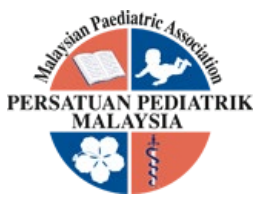

\title{
DELAYED DIAGNOSIS OF RARE CYANOTIC CARDIAC LESION IN A HYPOXEMIC BUT OTHERWISE ASYMPTOMATIC INFANT
}

\author{
Dayang Zuraini Sahadan, Ee Wei Ng, Yinn Khurn Ooi
}

\begin{abstract}
The causes of neonatal hypoxemia are usually either pulmonary or cardiac pathologies. We report a case of a 2-month-old boy with oxygen dependency since birth. He would desaturate down to $88-90 \%$ whenever supplemental oxygen was weaned off. Initial screening echocardiograms described only a small atrial septal defect, thus lung disease was thought to be the aetiology. Eventually, a detailed echocardiogram and CT angiography revealed anomalous right superior vena cava (RSVC) draining into the left atrium (LA). Echocardiography with bubble study injected via the upper extremities showed brisk filling of "bubbles" in the left heart, confirming fixed right-to-left shunting. Anomalous RSVC drainage into the LA is an extremely rare form of anomalous systemic venous drainage whereby unexplained hypoxemia is present and is sometimes the only clinical manifestation. Surgical correction of this anomaly is indicated to prevent complications of cyanosis and risk of systemic embolization. The surgery generally carries low risk and is associated with good long-term prognosis.
\end{abstract}

Keywords: Hypoxemia, Anomalous RSVC to LA Bubble Study, Right-to-left Shunt

\section{Introduction}

Hypoxemia is defined as abnormally low levels of oxygen in the blood. There are several mechanisms of hypoxemia which include ventilation/perfusion mismatch, right-to-left intra-cardiac shunts, diffusion impairment, hypoventilation and low environmental oxygen.

Anomalous right superior vena cava (RSVC) draining into the left atrium (LA) is a rare congenital cardiac anomaly which causes rightto-left shunting of all the systemic venous blood returning through the superior vena cava. This shunting of deoxygenated blood to the systemic arterial circulation then leads to unexplained persistent cyanosis or hypoxemia of varying severity. To date, there are only eleven children $[1,2,3,5,6,9,10]$ and sixteen adults reported in the literature $[3,4,5,7,8]$. Aside from aforementioned cyanosis, these patients are generally asymptomatic.
Received: 27 May 2020; Accepted revised manuscript: 13 September 2020

Published online: 28 October 2020

\section{Case Report}

A 2-month-old full term boy was referred to the paediatric respiratory unit for oxygen dependency. His antenatal period was uneventful and routine antenatal ultrasound scan was normal. He was delivered via emergency lower segment Caesarean section for macrosomia, with a birthweight of $4.1 \mathrm{~kg}$. He had a short history of ventilation ( 8 hours) for meconium aspiration syndrome postnatally. There were no concerns for persistent pulmonary hypertension of newborn and he was extubated to non-invasive ventilation modes and subsequently weaned to nasal oxygen at 8 days of life. Otherwise, he had

\footnotetext{
Department of Paediatrics, Hospital Serdang, Jalan Puchong 43000 Kajang, Selangor, Malaysia Corresponding Author: Dayang Zuraini Sahadan, Paediatric Department, Hospital Serdang Jalan Puchong 43000 Kajang, Selangor Tel: +603-89475555 Email:

Zuraini.Sahadan@gmail.com
} 
no history of congenital lung infection or other history to suggest congenital lung disorders. However, he would consistently develop hypoxemia whenever oxygen support was weaned off, despite breathing comfortably with no evidence of respiratory distress. He was able to maintain oxygen saturation above $95 \%$ with the presence of $2 \mathrm{~L} / \mathrm{min}$ nasal oxygen but would desaturate down to $88-90 \%$ on room air. He remained hemodynamically stable throughout. Clinically, he was not dysmorphic, well thrived and not tachypnoeic on air. He did not have extremity clubbing, chest deformity, or abnormal heart sounds including cardiac murmurs. His breath sounds were good without any other added sounds. Other systems were equally unremarkable.

Initial echocardiogram done in his peripheral birth hospital only reported a small atrial septal defect (ASD) without presence of pulmonary hypertension. His serial chest $\mathrm{X}$-rays and thoracic high-resolution computed tomography (HRCT) showed no significant pulmonary disease. In our tertiary centre, flexible bronchoscopy done showed only mild left lower bronchomalacia. Eventually, a detailed echocardiography via the segmental approach was done and revealed an anomalous RSVC draining into LA with mild enlargement of left sided chambers in addition to previously described small high secundum ASD. These findings were confirmed with Computed Tomography (CT) angiography. We also performed an echocardiogram with bubble study, which showed brisk filling of "bubbles" in the left heart, confirming our diagnosis of cyanotic heart disease with fixed right-to-left shunting.

With the diagnosis made, he was given an acceptable oxygen saturation range of more than $80 \%$. Oxygen therapy was ceased with this new lower oxygen saturation threshold. Pulse oximetry trend on room air showed mean saturation between $88-90 \%$ with stable heart rate 100-110 bpm and he was discharged well soon after. He was followed up in the outpatient setting, where he remained well and thriving. He underwent surgical repair successfully at 1 year old with an uneventful post-operative course. However, he did develop moderate RSVC obstruction secondary to anastomotic stricture a year post surgery during routine follow up echocardiogram, although he remains well without any symptoms of superior vena cava (SVC) syndrome. He was planned for balloon angioplasty of the stenosis via interventional cardiac catheterization later. 


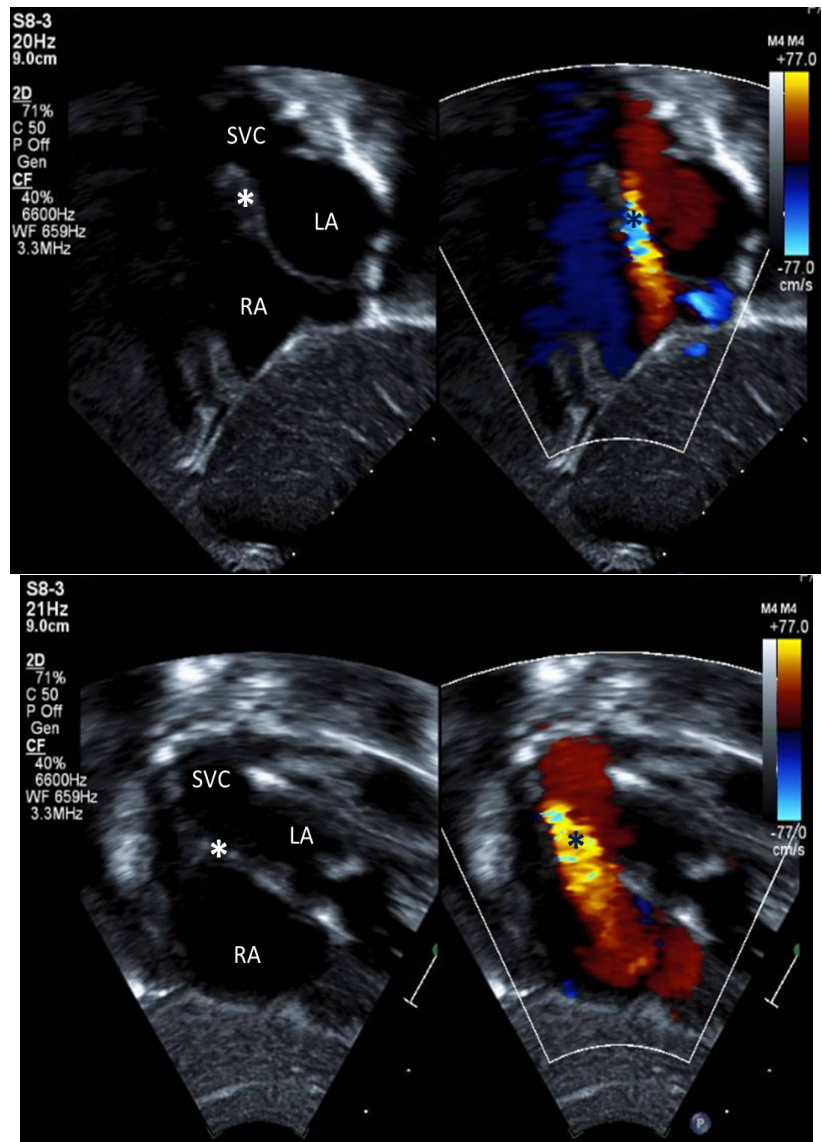

Figure 1. Sagittal and coronal view of echocardiography showing anomalous RSVC draining into LA. SVC (Superior Vena Cava); LA (Left Atrium); RA (Right Atrium); * Atrial septal defect (ASD).

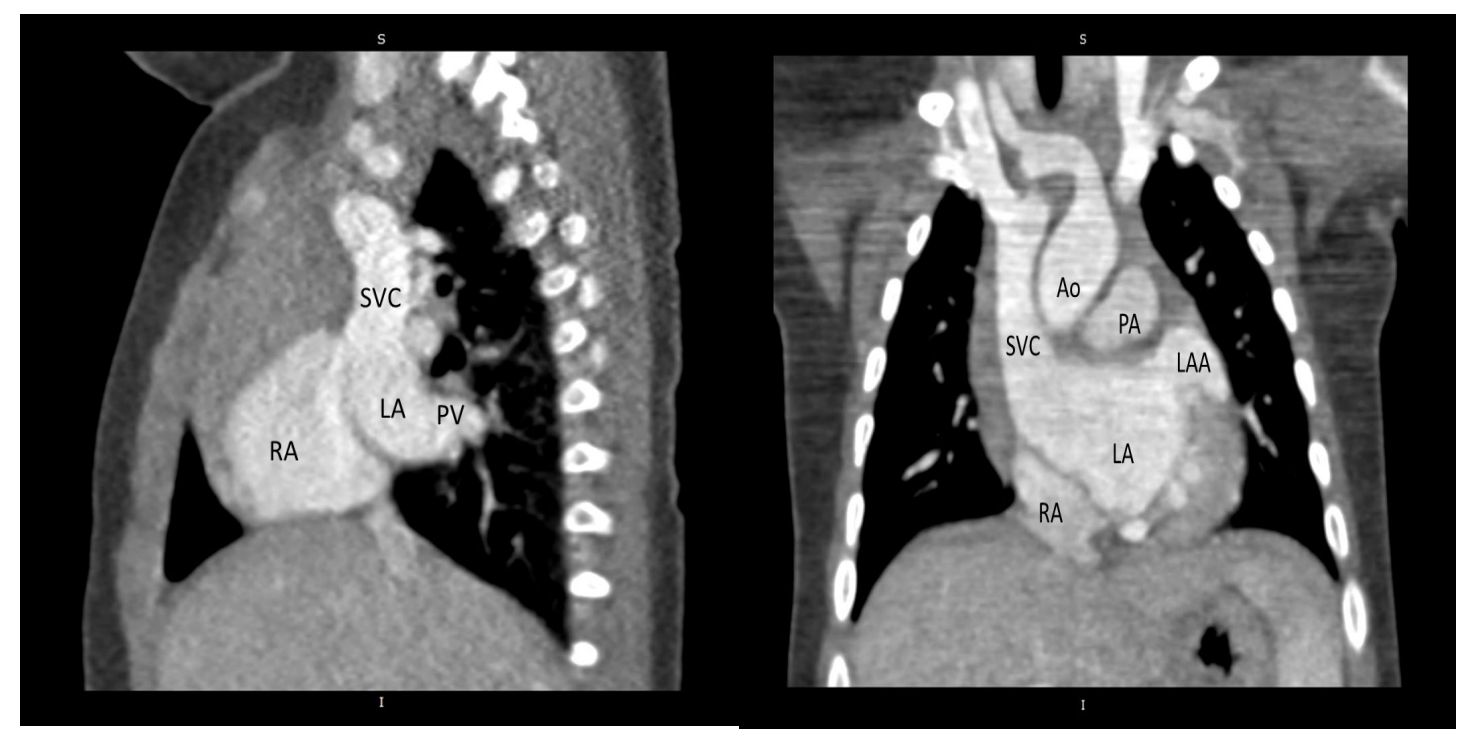

Figure 2. Computed tomography angiography (CTA) revealed anomalous RSVC draining into LA. SVC (Superior Vena Cava); LA (Left Atrium); RA (Right Atrium); LAA (Left Atrial Appendage); PV (pulmonary Vein); PA (Pulmonary Artery); Ao (Aorta). 


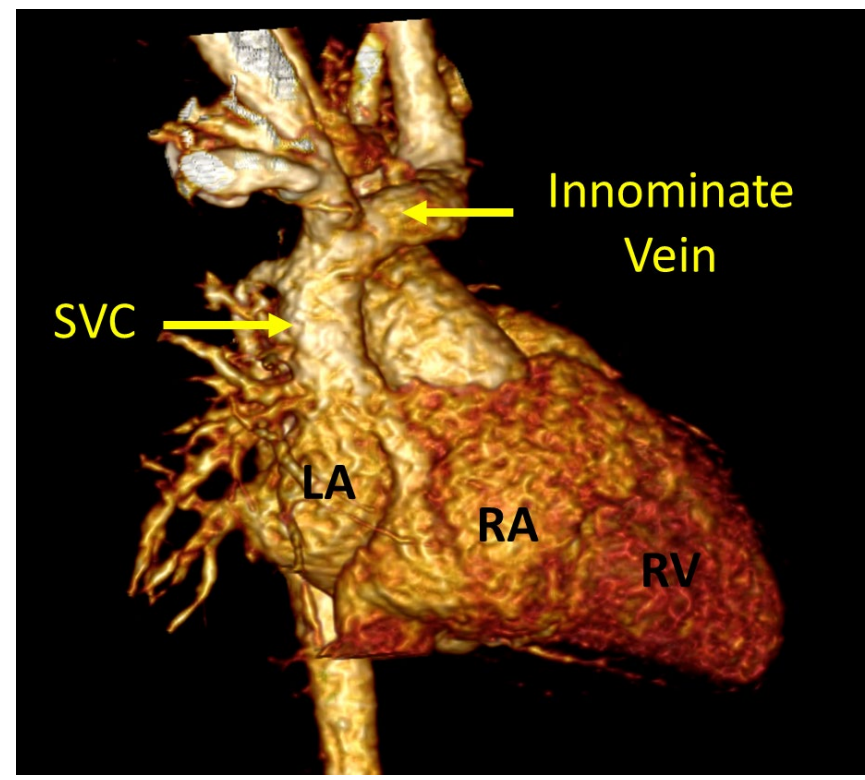

Figure 3. A 3-dimensional reconstruction of the CTA showing the RSVC connecting to LA. SVC (Superior Vena Cava); LA (Left Atrium); RA (Right Atrium); RV (Right Ventricle).
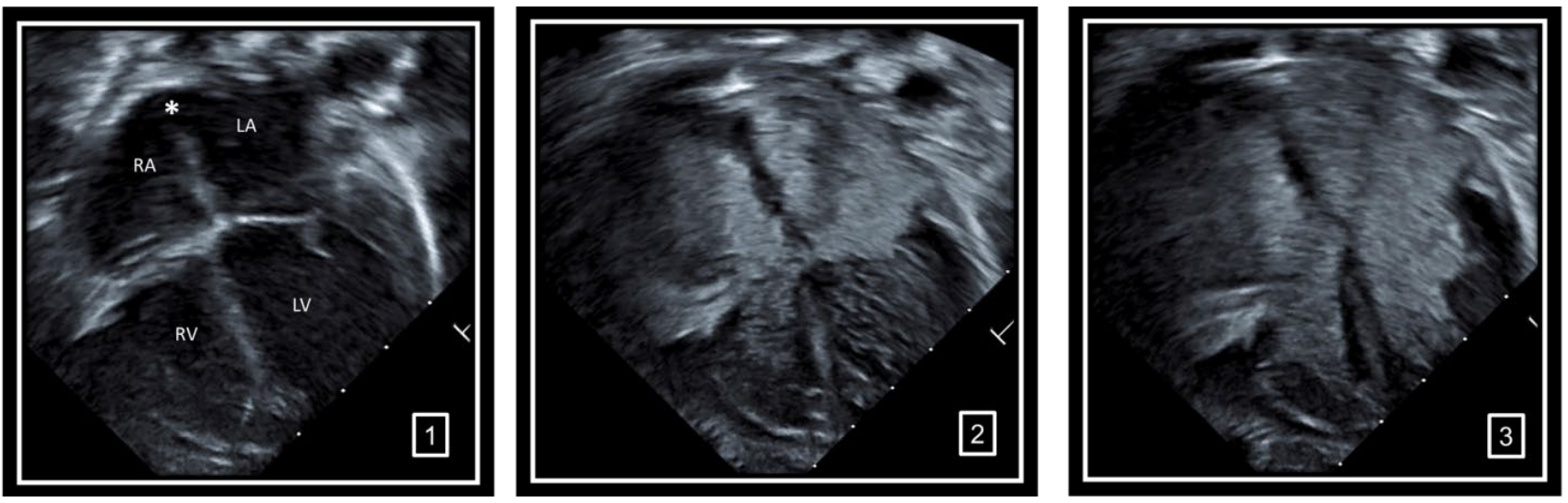

Figure 4. Transthoracic echocardiogram with bubble study - injection of agitated saline solution into the right subclavian venous line revealed rapid 'opacification' of the LA followed by RA 'opacification' via the ASD.

LA (Left Atrium); LV (Left Ventricle); RA (Right Atrium); RV (Right Ventricle); * Atrial septal defect (ASD).

\section{Discussion}

Systemic venous return anomalies are heterogeneous and very rare. It is estimated to have a prevalence of about $0.5 \%$ of all congenital heart diseases [1]. A persistent left SVC draining into the right atrium via a dilated coronary sinus is the most frequently seen anomaly of the thoracic veins. It is often found as an incidental echocardiographic finding without significant clinical consequences. Meanwhile, isolated anomalous drainage of the RSVC into the LA is an extremely rare congenital systemic venous malformation characterized by right-to-left shunt physiology.

Our case is one of the youngest patients diagnosed with anomalous drainage of the RSVC into the LA. He also had an associated small secundum atrial septal defect. The patient was referred appropriately for early echocardiographic cardiac assessment to rule out cyanotic congenital heart disease. However, the diagnosis was missed as serial echocardiography done was targeted at examining for common cyanotic heart lesions. There was a lack of 
operator awareness of potential anomalous systemic venous drainage pathologies due to its rarity. Detailed echocardiography coupled with CTA and bubble study was able to accurately diagnose the abnormality. Hence we feel that it is important to publish this case report, to spread awareness of this very rare but important disease amongst our peers and colleagues.

Children with this anomaly may present with variable degrees of hypoxemia with normal growth and development while adult patients may experience chronic headaches, lightheadedness, dyspnoea and easy fatigability. There were also cases of brain abscesses reported among patients with this anomaly $[3,4,5]$. Some of the cases were associated with heterotaxy syndromes (isomerism) and other congenital heart defects [2,3]. The commonly associated cardiac malformations include atrial or ventricular septal defects and patent ductus arteriosus. However when associated with heterotaxy syndrome, there can be a wide variety of presentations, including but not limited to atrioventricular septal defects, single ventricle, tetralogy of Fallot, transposition of the great arteries and abnormalities of the inferior vena cava (IVC) or pulmonary venous system [12].

The embryological mechanism of this RSVC anomaly is not clearly understood. It may result from a malposition of sinus venosus with a relative leftward and cephalad movement of the aperture of the future superior vena cava [11]. Alternatively, it is proposed that the cephalic portion of the right valve of the sinus venosus fuses with the atrial septum superior to the coronary sinus inlet that prevents the SVC from draining into the RA $[8,12]$. Van Praagh believes that it resulted from a deficiency in the wall that is shared by the right SVC and the right upper pulmonary veins [13].
Diagnosis can be made by various imaging modalities, from the simplest, echocardiography [16] with or without bubble study, contrastenhanced CT or cardiac MRI to more invasive techniques such as cardiac catheterization [1]. When available, foetal echocardiography can also be a useful prenatal diagnostic tool. The defect can be best visualized on longitudinal bi-caval view as a posteriorly deviated SVC connecting abnormally to the LA [13]. On many occasions, echocardiography is limited by the poor acoustic window or by operator variability. Contrast echocardiography with bubble study adds much value to the diagnosis. Injection of agitated normal saline through a vein in the upper limb will result in the immediate appearance of microbubbles in the left atrium.

The presence of right-to-left shunt increases the risk for cerebral embolism or brain abscess. Out of the cases reported in the literature, 20\% were complicated by brain abscess [4], highlighting the importance of recognizing this rare condition. Conversely, in patients who present with brain abscess, cryptogenic stroke or recurrent unexplained seizures, thorough investigations should be done to identify right-to-left shunt pathologies. Once diagnosed, these defects should be surgically corrected if feasible.

Intra-operatively, it is important to ascertain that there is no abnormal pulmonary venous drainage, and care should be taken to prevent any stenosis of the SVC-RA connection [2]. One potential immediate postoperative complication is transient right heart failure due to sudden volume overload in the relatively hypoplastic right ventricle that may be present in patients with this anomaly [3]. Generally, surgical correction of this rare cardiac lesion is of low risk and is associated with good long-term prognosis. 
Table 1. Summary of previous reported cases of anomalous RSVC to LA among children

\begin{tabular}{|c|c|c|c|c|c|}
\hline Author & Year & Age & Gender & Features & Diagnosis \\
\hline Wood [17] & 1956 & 10 & $\mathrm{~F}$ & $\begin{array}{l}\text { Cyanosis, no } \\
\text { clubbing }\end{array}$ & Catheterization \\
\hline Kirsch [11] & 1961 & 2 & $\mathrm{~F}$ & Clubbing & Catheterization \\
\hline Braudo [12] & 1968 & 3 & $\mathrm{~F}$ & $\begin{array}{l}\text { Clubbing, } \\
\text { murmur, JV } \\
\text { distension }\end{array}$ & Catheterization \\
\hline Perez [19] & 1979 & $7 / 12$ & M & $\begin{array}{l}\text { Cyanosis, } \\
\text { murmur }\end{array}$ & Catheterization \\
\hline Tomoe [18] & 1980 & 1 & $\mathrm{~F}$ & $\begin{array}{l}\text { Cyanosis, } \\
\text { clubbing }\end{array}$ & $\begin{array}{l}\text { Echocardiography } \\
\text { with bubble study }\end{array}$ \\
\hline Thivolle [20] & 1980 & 14 & M & Brain abscess & $\begin{array}{l}\text { Radionuclide } \\
\text { angiography }\end{array}$ \\
\hline Truman [5] & 1981 & $8 / 12$ & $\mathrm{~F}$ & Cyanosis & Catheterization \\
\hline Singh [6] & 2008 & 11 & $\mathrm{~F}$ & $\begin{array}{l}\text { Brain abscess, } \\
\text { recurrent } \\
\text { seizures }\end{array}$ & $\begin{array}{l}\text { Echocardiography } \\
\text { with bubble study }\end{array}$ \\
\hline Moradian [2] & 2017 & 8 & $\mathrm{~F}$ & Mild cyanosis & $\begin{array}{l}\text { Echocardiography } \\
\text { with bubble study, } \\
\text { cardiac } \\
\text { catheterization }\end{array}$ \\
\hline Khoshhal [9] & 2019 & $18 / 12$ & M & $\begin{array}{l}\text { Persistent } \\
\text { hypoxia }\end{array}$ & $\begin{array}{l}\text { Echocardiography } \\
\text { with bubble study, } \\
\text { cardiac } \\
\text { catheterization }\end{array}$ \\
\hline $\begin{array}{l}\text { Rashmi Gulati } \\
\text { [10] }\end{array}$ & 2020 & $13 / 12$ & $\mathrm{~F}$ & $\begin{array}{l}\text { Persistent } \\
\text { hypoxia }\end{array}$ & $\begin{array}{l}\text { Echocardiography } \\
\text { with bubble study }\end{array}$ \\
\hline Present study & & $2 / 12$ & $M$ & $\begin{array}{l}\text { Persistent } \\
\text { hypoxia }\end{array}$ & $\begin{array}{l}\text { Contrast CT } \\
\text { angiography, } \\
\text { Echocardiography } \\
\text { with bubble study }\end{array}$ \\
\hline
\end{tabular}




\section{Conclusion}

Awareness and high clinical suspicion are important for the early diagnosis of anomalous RSVC draining into LA to prevent prolonged hospitalization, inappropriate oxygen therapy or even ventilation.

We believe that in dealing with unexplained hypoxemia in a child, echocardiography as a noninvasive screening test is invaluable, especially when the segmental approach is used. Additionally, using bubble study will help to confirm (or disprove) the diagnosis.

Regardless of the clinical presentation, surgical correction is indicated once the diagnosis of systemic venous connection to the LA is made. This is to avoid complications of cyanosis and the risk of systemic embolization. The surgery itself generally carries low risk and is associated with good long-term prognosis.

\section{Ethical consideration}

Consent was taken from the patient. All data collected were kept confidential.

\section{Disclaimer}

The views, interpretations, implications, conclusions, and recommendations expressed in this case report are those of the authors alone and do not necessarily represent the opinions nor the views or policy of the Ministry of Health Malaysia.

\section{Acknowledgement}

We would like to express our sincere gratitude to all team members of Paediatric Respiratory Unit and Paediatric Cardiology Unit, Serdang Hospital for managing this patient. We would also like to thank Assoc. Prof Dr Faizah Mohd Zaki for helping in the reconstruction of $\mathrm{CT}$ angiography images.

\section{References}

[1] Chessa M, Carminati M, Cinteza E, Butera G, Giugno L, Arcidiacono C, et al. Partial abnormal drainage of superior and inferior caval veins into the left atrium: two case reports. Rom J Morphol Embryol. 2016;57(2):559-62.

[2] Moradian M, Mortezaeian H, Baghaei R, Ghadrdoost B. Left atrial drainage of the right superior vena cava: a case report. J Tehran Univ Heart Center. 2018;13(2):84-7.

[3] Park $H$, Summerer $M$, Preuss $K$, Armstrong WF, Mahomed Y, Hamilton DJ. Anomalous drainage of the right superior vena cava into the left atrium. Journal of the American College of Cardiology. 1983;2(2):358-62.

[4] Usalp S, Karaci A, Balcı K, Yazicioglu V, Baskurt $\mathrm{M}$, Arat Koc N. Right superior vena cava draining into the left atrium. Clinical Medical Reviews and Case Reports. 2016; 3(10):314.

[5] Truman A, Rao P, Kulangara R. Use of contrast echocardiography in diagnosis of anomalous connection of right superior vena cava to left atrium. Heart. 1980; 44(6):718-23.

[6] Singh S, Geelani M, Modi P. Anomalous connection of superior vena cava to the left atrium masquerading as epilepsy: A case report with review of literature. Annals of Cardiac Anaesthesia. 2008;11(1):42-5.

[7] Cohen D, Reiner J, Ahari J, Lewis J. Isolated right superior vena cava into the left atrium detected by contrast echocardiography. Circulation. 2013;128(10):1129-30.

[8] Baggett C, Skeen SJ, Gantt DS, Trotter BR, Birkemeier KL. Isolated right superior vena cava drainage into the left atrium diagnosed noninvasively in the peripartum period. Tex Heart Inst J. 2009;36: 611-4.

[9] Khoshhal, S. Anomalous connection of the right superior vena cava to the left atrium in a child with bilateral superior vena cavae: An unusual cause of cyanosis. Pediatr Cardiol. 2018;40:226-9.

[10] Gulati R, Smith T, Siow M, Batten L. Isolated right superior vena cava drainage into the left atrium: An uncommon cause of persistent hypoxia in a neonate. Echocardiography. 2020;37(4):641-5.

[11] Kirsch WM, Carlsson E, Hartmann AF Jr. A case of anomalous drainage of the superior vena 
cava into the left atrium. J Thorac Cardiovasc Surg. 1961;41:550-6.

[12] Braudo M, Beanlands DS, Trusler G. Anomalous drainage of the right superior vena cava into the left atrium. Can Med Assoc J. 1968;99(14):715-9.

[13] Van Praagh S, Geva T, Lock JE, Nido PJ, Vance MS, Van Praagh R. Biatrial or left atrial drainage of the right superior vena cava: anatomic, morphogenetic, and surgical considerations - report of three new cases and literature review. Pediatr Cardiol. 2003;24(4):350-63.

[14] Vassallo M, Pascotto M, Pisacane C, Santoro $G$, Paladini D, Russo MG, et al. Right superior vena cava draining into the left atrium: prenatal diagnosis and postnatal management. Ultrasound Obstet Gynecol 2006; 27:445-8.

[15] Huhta JC, Smallhorn JF, Macartney FJ, Anderson $\mathrm{RH}$, de Leval M. Cross-sectional echocardiographic diagnosis of systemic venous return. Br Heart J, 1982, 48(4):388403.
[16] Butera G, Salvia J, Carminati M. When side matters: contrast echocardiography with injection from the left antecubital vein to detect a persistent left superior vena cava draining to the left atrium in a patient with cerebral stroke. Circulation, 2012, 125(1).

[17] Wood P. Diseases of the heart and circulation. 2nd ed. Philadelphia: Lippincott, 1956:457-8.

[18] Tomoe A, Yoshida Y, Ogata H, Chen HC, Fukuda $M$. Peripheral contrast echocardiographic findings of anomalous drainage of the right superior vena cava into the left atrium. Tohoku J Exp Med. 1980; $130: 353-8$

[19] Vazquez-Perez J, Frontera-Izquierdo P. Anomalous drainage of the right superior vena cava into the left atrium as an isolated anomaly. Rare case report. Am Heart J. 1979;97:89-91.

[20] Thivolle P, Munsch RC, Veillas G, Dahoun A, Berger $M$. Cardiopulmonary flow studies show venous retum from upper half of body passing directly to left atrium [Letter]. J Nucl Med. 1980;21:293-4. 